\title{
Variable-oriented and person-oriented perspectives of analysis: The example of alcohol consumption in adolescence
}

\author{
Alexander von Eye ${ }^{\mathrm{a}, *}$, G. Anne Bogat ${ }^{\mathrm{a}}$, Jean E. Rhodes ${ }^{\mathrm{b}}$ \\ ${ }^{a}$ Department of Psychology, Michigan State University, East Lansing, MI, USA \\ ${ }^{\mathrm{b}}$ University of Massachusetts, Boston, USA
}

\begin{abstract}
This article presents person-oriented and variable-oriented approaches to data analysis. To illustrate these two approaches and the types of information they provide the researcher, data from 3558 control group youth from the National Cross-Site Evaluation of High Risk Youth Programs were analysed. The relationship, over time, between parent attitudes and gender as it relates to youth alcohol consumption were examined. Data were analysed and compared using a variable-oriented approach (repeated measures ANOVA) and a person-oriented approach (Configural Frequency Analysis). Data analysis demonstrated that variable- and person-oriented approaches provide the researcher with different information that can be complementary. The ANOVA identified an overall trend that accounted for little variance; the CFA explained why this was the case by identifying groups of respondents whose behaviour was different from the overall trend. The implications of these results and the use of both types of approaches are discussed. (C) 2006 The Association for Professionals in Services for Adolescents. Published by Elsevier Ltd. All rights reserved.
\end{abstract}

Keywords: Variable orientation; Person orientation; Adolescent; Alcohol; Competence

\footnotetext{
*Corresponding author. Tel.: + 15173553408.

E-mail address: voneye@msu.edu (A. von Eye).
}

0140-1971/\$30.00 (C) 2006 The Association for Professionals in Services for Adolescents. Published by Elsevier Ltd. All rights reserved.

doi:10.1016/j.adolescence.2006.06.007 


\section{Introduction}

The major goal of this article is to illustrate and compare the kinds of statements that can be made using two complementary approaches to data analysis, the variable-oriented and the person-oriented approaches. In order to illustrate these two approaches, we use data from the National Cross-Site Evaluation of High Risk Youth Programs (Springer, Sale, Nistler, Kasim, \& Pan, 2000) to ask questions regarding what makes youth resilient to alcohol consumption. Repeated measures ANOVAs, the variable-oriented approach, illustrate the effects of parental attitudes as predictors of alcohol consumption relative to time, gender, and their interactions. We will show that these results, although statistically significant, carry no more than modest explanatory value, expressed in units of measures of effect size. Therefore, we assume that variable relationships are not uniform across the range of all values under study. To test this assumption, we then use a person-oriented approach, Configural Frequency Analyses (CFA; Lienert \& Krauth, 1975; von Eye, 2002), to identify where, locally, variable relationships are the strongest among subpopulations, rather than the entire population.

\section{The person-oriented vs. variable-oriented approach to data analysis}

Standard hypotheses in psychological research and standard methods of data analysis express statements in terms of variables. For example, the statement: there is a correlation between parental attitudes toward adolescent drinking and the amount of alcohol consumed by adolescents ${ }^{1}$ operates at the variable level. Inter-individual differences are brushed aside or, in more technical terms, considered random and thus negligible. The data analysis that leads to such a statement typically compares the sample means of specific variables.

In contrast, person-oriented research focuses on individuals or homogeneous subgroups of individuals. In his manifesto on psychology as an idiographic science, Molenaar (2004) emphasizes the necessity of considering inter-individual differences and suggests bringing back the individual into psychological research. In a parallel fashion, Bergman and collaborators (Bergman \& Magnusson, 1997; von Eye \& Bergman, 2003) posit six tenets, the most fundamental of which is that functioning and development are, at least in part, specific and unique to the individual. The implications of these propositions are clear. If, for a valid description and explanation of behaviour and development, it is important to take into account that results can differ across individuals, then aggregate level statements are in danger of being at least incomplete. For instance, von Eye and Bergman (2003) showed that, in a (small) sample of adult alcoholics, the autocorrelation pattern of beer consumption that had been created at the aggregate level did not validly describe the autocorrelation pattern of a single individual in the sample.

\section{Research examples}

Examples abound in which researchers show that individuals and groups of individuals differ from each other in important parameters that describe development, function, dimensional

\footnotetext{
${ }^{1}$ In the data analysed in this article, this correlation is -0.336 , indicating that more negative parental attitudes correlate with less drinking.
} 
characteristics, and the meaning of behaviour and variables. For example, in the adolescent health domain, using data from a study by Finkelstein, von Eye, and Preece (1994), von Eye and Bergman (2003) showed that the cross-lagged correlation structure of the development of physical characteristics and aggression in puberty differs for boys and girls, and, in addition, each gender group's structure differed from the structure that was estimated for the aggregate sample.

Validation of the existence of subgroups occurs when it can be shown that they differ on relevant variables that were not used to form the groups. For example, Tubman and collaborators (Tubman, Vicary, von Eye, \& Lerner, 1990, 1991; Tubman, Wagner, \& Langer, 2003) found that subgroups with different patterns of longitudinal drug or alcohol consumption exist and that these subgroups differ in sexual behaviour and such psychiatric symptoms as depression. Applying the same methodology to data from the NYLS (Thomas \& Chess, 1986), Tubman, Lerner, Lerner, and von Eye (1992) showed that groups of adolescents with different temperament development exist, and that these subtypes differ in psychosocial adjustment. Specifically, the authors showed that extremely difficult temperament is associated with poorer psychosocial functioning in childhood and young adulthood.

In the following sections, we present two analyses of the same data. The first analysis adopts a variable orientation. Data are analysed at the aggregate level, and results are expressed in terms of effects of variables. Using ANOVA methods, we ask questions concerning mean differences. The second analysis follows exclusively a person orientation. Using CFA (Lienert \& Krauth, 1975; von Eye, 2002), we ask questions concerning the frequencies with which configurations of crossed categorical variables were observed. Before we present the data analyses, we summarize the extant literature on parental attitudes as predictors of alcohol consumption relative to time, gender, and their interactions.

\section{Alcohol consumption in adolescence}

The use of alcohol is widespread among adolescents. For example, in their annual survey, Johnston, O'Malley, and Bachman (2003) found that by 8th grade, 31\% of youth have tried alcohol. Moreover, nearly $20 \%$ of the surveyed 8 th-graders reported having at least one drink in the past month, with $14.5 \%$ having been drunk at least once in the past year (Johnston et al., 2003). In addition to being illegal, youthful drinking poses a host of individual and societal risks ranging from cognitive impairment to alcohol-related injuries and fatalities (O'Malley, Johnston, \& Bachman, 1998).

It is important to identify those youth who do not engage in alcohol abuse. Socially competent youth engage in more responsible behaviour, including lower rates of substance use (Griffin, Epstein, Botvin, \& Spoth, 2001; Scheier, Botvin, Diaz, \& Griffin, 1999; for the role of competence in adolescent development in general, see Theokas et al., 2005; Lerner et al., 2005). For example, competence (self- and teacher-rated) in 3rd and 5th graders was negatively associated with the use of alcohol (Jackson, Henriksen, Dickinson, \& Levine, 1997). Effective parenting (in part defined by appropriate rule setting and supervision) was also associated with less alcohol use. Our paper examines two factors associated with the absence of youth alcohol consumption-parent attitudes and gender. 
Parents have an important effect on adolescent substance use (Andrews, Hops, Ary, Tildesey, \& Harris, 1993). A number of studies has found a significant relationship between parent attitudes toward alcohol use and the use of alcohol by their children (e.g., Ary, Tildesley, Hops, \& Andrews, 1993; Halebsky, 1987). Yu (1998) argued that the influence is strongest among underage youth when they are living with their parents and, thus, in close proximity. In addition, in a crosssectional study, Yu (2003) found that children were more likely to use alcohol when they believed that their parents did not have negative attitudes about underage drinking. In a study on parental monitoring of alcohol use, Bogenschneider, Wu, Raffaelli, and Tsay (1998) found that fathers' monitoring of alcohol use directly influenced alcohol consumption. However, the effect was strongest for those fathers who also intensely disapproved of alcohol use.

Petraitis, Flay, and Miller (1995), in their review of theories of adolescent substance use, note that gender has been widely ignored by extant theorists, even though clear gender differences exist. For example, studies have consistently indicated that males consume alcohol more frequently and in greater quantity during each episode than do females (e.g., Johnston et al., 2003; Robins \& Martin, 1993; Thomas, 1996). Other research indicates that patterns of parent/child drinking are more similar for same-gender pairs (e.g., Yu \& Perrine, 1997) and that more girls than boys believe that parents monitor their consumption of alcohol (Webb, Bray, Getz, \& Adams, 2002). Thus, parent attitudes may be a more potent influence on girls' alcohol consumption.

Parent attitudes as they differentially effect boys' and girls' alcohol consumption are rarely studied. One cross-sectional study found no gender differences in the relationship between parent attitudes and alcohol consumption (Fitzgerald \& Arndt, 2003). Unfortunately, many studies of parent attitudes and alcohol consumption simply control for gender along with other demographic variables (e.g., Yu, 2003).

\section{The study}

\section{Methods}

The data reported here were collected as part of the National Cross-Site Evaluation of High Risk Youth Programs (HRY; Springer et al., 2000). The goal of the evaluation was to examine the effectiveness of prevention programs that were funded by the Center for Substance Abuse Prevention (CSAP) in 1994 and 1995. This five-year national study was conducted from 1995 to 2000 by EMT Associates, Inc. and Macro International, Inc. Participants from the 48 sites included more than 10,500 nine to 18 year-olds from a wide variety of ethnic and cultural backgrounds. Among the participants, 6031 participated in CSAP prevention programs, and 4579 served as a comparison group. Youth in the comparison group were drawn from the same community in which the HRY program was offered, but did not receive services from the program. The youth were characterized as at-risk based primarily upon socioeconomic background. Program-level information describes lower- to lower-middle class communities characterized by poverty, high crime rates, and ambient substance use rates. 


\section{Sample}

Only control group participants with complete data were included in the present data analysis $(N=3558)$. Females $(67.7 \%)$ and members of ethnic minority groups $(79.2 \%)$ accounted for more than half of the sample size. About one-third $(30.3 \%)$ of participants were AfricanAmerican, 25.1\% Latino, 8.3\% Native American, 12\% non-Latino White, 14.5\% Asian or Pacific Islander, and $1 \%$ mixed race. Information for $8.8 \%$ of the participants was not available. The mean age of the participants was 12.76 (s.D. $=2.14$ ), and their ages ranged from 9 to 18 .

\section{Measures}

The questions derived from proven measurement items, or subsets of measurement items, from existing instruments. Measures were selected for appropriate content and psychometric quality (i.e., demonstrated reliability and validity in appropriate populations). For purposes of this study, we focused on the youths' demographic characteristics, alcohol use, and perceptions of parental attitudes toward drinking.

\section{Demographic characteristics}

Demographic information including gender (male $=1$, female $=2$ ) and race/ethnicity were asked of each youth.

\section{Alcohol use}

The following question assessed participants' alcohol use: "On how many DAYS did you have an alcoholic drink in the LAST MONTH (30 days)? (By a drink, we mean a can of beer, a glass of wine, a wine cooler, or a shot of hard liquor.)" Participants selected "none," "1 or 2 days in the last month," "3 to 5 days in the last month," "6 to 9 days in the last month," "10 to 19 days in the last month," or "20-31 days in the last month."

\section{Parental attitudes toward drinking}

The 3-item questionnaire had four ordinal categories, with 1 indicating that adolescents believe that their parents "would not be upset at all," 2 indicating "a little upset," 3 indicating "pretty upset," and 4 indicating their parents would be "very upset" by their drinking.

\section{Procedures}

Parental consent was obtained prior to data collection. The data presented here were obtained at two time points (at the time corresponding to program entry and program exit). The average length of time between these two time periods was 4.46 months. This instrument was developed by the CSAP especially for this study. The questionnaire was available in both English and Spanish. 


\section{Results}

Descriptive analysis of adolescent alcohol consumption data

For the following analyses, we selected four variables. The dependent variables were days drinking in the last month (Alcohol Consumption) at Time 1 and Time 2. The independent variables were adolescent-reported parental feelings toward the respondent adolescent's drinking (Parental Attitudes) and Gender. Descriptive information about these variables appears in Table 1.

Table 1

Descriptive statistics of alcohol consumption in the last month: Time $\times$ Parental attitudes $\times$ Gender cross-classification

\begin{tabular}{|c|c|c|c|c|c|}
\hline & Gender & Parents feel about you drinking & Mean & S.D. & $N$ \\
\hline \multirow[t]{15}{*}{ How much alcohol in last month (T1) } & \multirow[t]{5}{*}{ Male } & They would not be upset at all & 2.16 & 1.399 & 58 \\
\hline & & They would be a little upset & 2.40 & 1.656 & 101 \\
\hline & & They would be pretty upset & 1.99 & 1.549 & 171 \\
\hline & & They would be very upset & 1.24 & 0.757 & 818 \\
\hline & & Total & 1.50 & 1.130 & 1148 \\
\hline & \multirow[t]{5}{*}{ Female } & They would not be upset at all & 1.92 & 1.178 & 100 \\
\hline & & They would be a little upset & 1.86 & 1.237 & 192 \\
\hline & & They would be pretty upset & 1.38 & 0.754 & 272 \\
\hline & & They would be very upset & 1.15 & 0.552 & 1846 \\
\hline & & Total & 1.26 & 0.731 & 2410 \\
\hline & \multirow[t]{5}{*}{ Total } & They would not be upset at all & 2.01 & 1.264 & 158 \\
\hline & & They would be a little upset & 2.05 & 1.416 & 293 \\
\hline & & They would be pretty upset & 1.61 & 1.166 & 443 \\
\hline & & They would be very upset & 1.17 & 0.623 & 2664 \\
\hline & & Total & 1.34 & 0.886 & 3558 \\
\hline \multirow[t]{15}{*}{ How much alcohol in last month (T2) } & \multirow[t]{5}{*}{ Male } & They would not be upset at all & 1.91 & 1.466 & 58 \\
\hline & & They would be a little upset & 1.64 & 1.221 & 101 \\
\hline & & They would be pretty upset & 1.58 & 1.231 & 171 \\
\hline & & They would be very upset & 1.21 & 0.707 & 818 \\
\hline & & Total & 1.34 & 0.929 & 1148 \\
\hline & \multirow[t]{5}{*}{ Female } & They would not be upset at all & 1.60 & 1.005 & 100 \\
\hline & & They would be a little upset & 1.88 & 1.198 & 192 \\
\hline & & They would be pretty upset & 1.43 & 0.890 & 272 \\
\hline & & They would be very upset & 1.21 & 0.657 & 1846 \\
\hline & & Total & 1.30 & 0.783 & 2410 \\
\hline & \multirow[t]{5}{*}{ Total } & They would not be upset at all & 1.72 & 1.200 & 158 \\
\hline & & They would be a little upset & 1.80 & 1.209 & 293 \\
\hline & & They would be pretty upset & 1.49 & 1.036 & 443 \\
\hline & & They would be very upset & 1.21 & 0.672 & 2664 \\
\hline & & Total & 1.31 & 0.833 & 3558 \\
\hline
\end{tabular}


The means in Table 1 suggest that, in most categories for the parental attitude variable, males indicate that they drink more than females. In addition, the amount of drinking seems to go down in the male sample from Time 1 to Time 2, whereas it varies in the female sample depending on parental attitudes. The relationships between parental attitudes and alcohol consumption are depicted, by gender, for Time 1 in Fig. 1, and for Time 2 in Fig. 2.

Both Figs. 1 and 2 suggest that those adolescents who anticipate that their parents would be upset if the adolescent would drink, report lower levels of alcohol consumption. This relationship seems to be non-linear such that the decrease is stronger above the mean of the parental attitude scale. This is most pronounced in the responses in the male sample at Time 1 . In the following section, we ask whether these impressions that are based on descriptive information hold up when subjected to an ANOVA.

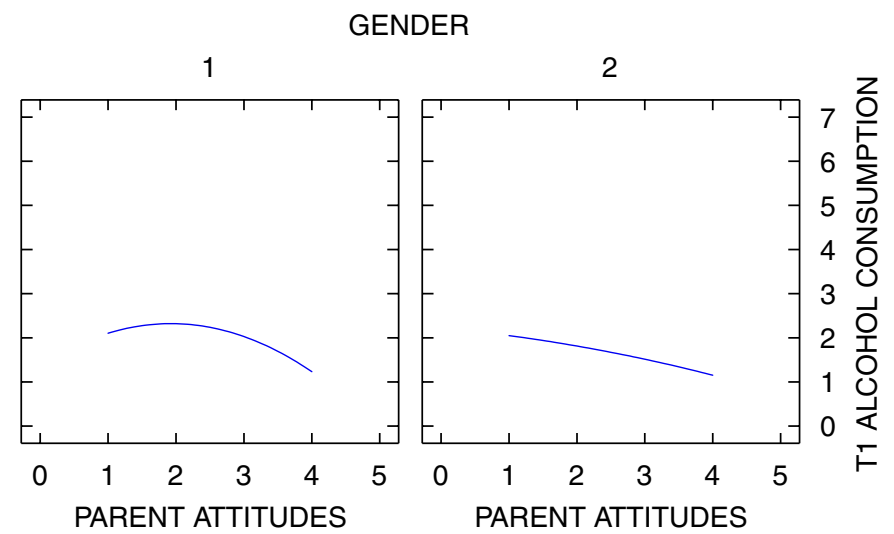

Fig. 1. Parental Attitudes and Alcohol Consumption Time $1 \times$ Gender $(1=$ males; $2=$ females $)$.

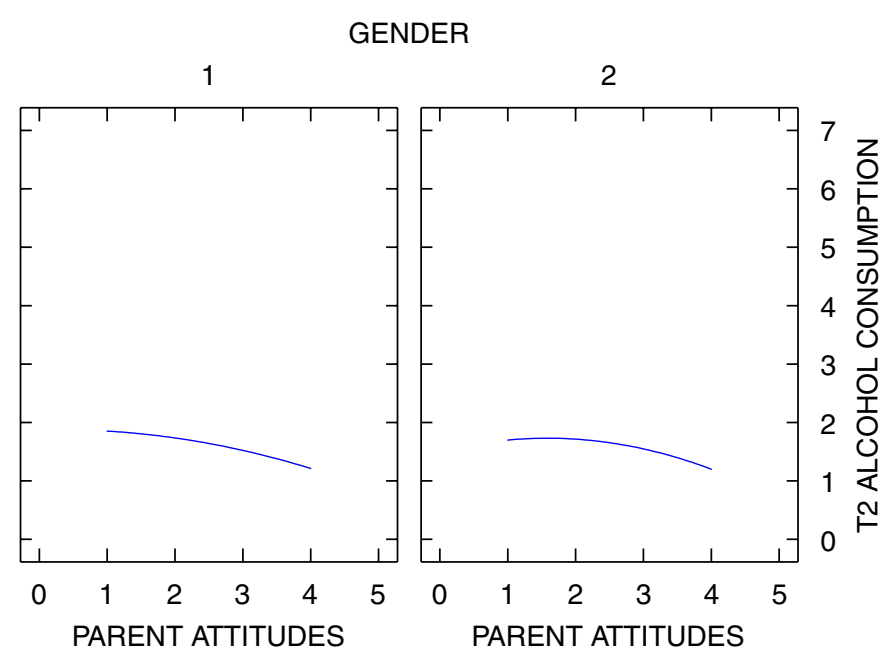

Fig. 2. Parental Attitudes and Alcohol Consumption at Time $2 \times$ Gender $(1=$ males; $2=$ females $)$. 


\section{Variable-oriented analyses: ANOVA}

In this section, we report the results of a mixed effect, repeated measures ANOVA. A repeated measures ANOVA can have variable-and person-oriented aspects. In the analyses that follow, we examine whether there is a mean observed difference in the amount of alcohol consumed by boys and girls. The linear slope determines whether the amount of alcohol increases, decreases, or stays constant over time. This is variable-oriented because the slope is determined to be the same for each participant and, more importantly, the curves describe the effects of one variable on another. ANOVA can answer questions concerning mean differences. At the level of main effects, mean differences are traced back to categories of single variables. At the level of interactions, mean differences are traced back to bi- or trivariate, or more complex variable patterns.

Why is it that any research question that examines the differences between boys and girls, and its ensuing data analysis, is not necessarily person-oriented? The person orientation is certainly concerned with understanding groups of individuals as compared to understanding variables that describe an entire sample. Gender is a natural grouping. Variable-oriented approaches to group differences between males and females (e.g., ANOVA) assume that gender groups are homogeneous. In contrast, person-oriented approaches to group differences assume that there may be important subgroups within a gender group that systematically differ from the group as a whole. We demonstrate this later, in the person orientation section of the article.

In the following section, when we ask whether the linear slope is the same for male and female adolescents, we are asking a variable-oriented question: Is the slope gender specific? In other words, does gender serve as a moderator? This is a variable-oriented approach, because we assume the groups are homogeneous. Thus, in the following discussion, we will focus solely on the variable-oriented aspects of ANOVA to serve as a contrast to the person orientation approach that we take in the subsequent section. (See von Eye \& Bogat, 2005 for an extended discussion of the variable and person oriented components of ANOVA.)

We treated the variables Time (Alcohol Consumption at T1 and T2), Parental Attitudes, and Gender as factors of a $2 \times 4 \times 2$ repeated measures ANOVA. A selection of the multivariate tests of the within-subjects effects in this analysis appears in Table 2.

Table 2 suggests that all within-subject effects are significant, and that the observed power is maximal. However, the effect sizes are very small throughout. As far as the within-subjects effects are concerned, we seem to face the situation in which a large sample suggests the existence of effects. These effects, however, explain only minimal portions of the observed variance of the dependent measures. Table 3 presents the ANOVA table for the within-subjects contrasts.

The results in Table 3 suggest that, overall, adolescents indicate that they drink less at Time 2 than at Time 1 (Time effect). Negative parental attitudes toward drinking result in smaller reported amounts of drinking, but more so at Time 1 than at Time 2 (see Figs. 1 and 2; Time $\times$ Parental Attitudes interaction). There is a Time by Gender interaction as indicated above: whereas boys report a reduction in the reported amount of consumed alcohol, girls report a slight increase (see Table 1) (Time $\times$ Gender interaction in Table 3). Finally, we find that the Time $\times$ Parental Attitudes interaction is gender-specific (Time $\times$ Gender $\times$ Parental Attitudes interaction). Whereas at Time 1 , the effect of parental attitudes is stronger in the boys' reports than in the girls' reports, at Time 2, the effect is the same (see Figs. 1 and 2). Table 4 displays the tests of the between-subjects effects. 
Table 2

Multivariate within-subject test results of the repeated measures ANOVA of the adolescent alcohol consumption data

\begin{tabular}{|c|c|c|c|c|c|c|c|c|}
\hline Effect & & Value & $F$ & $\begin{array}{l}\text { Hypothesis } \\
\text { df }\end{array}$ & $\begin{array}{l}\text { Error } \\
\text { df }\end{array}$ & Sig. & $\begin{array}{l}\text { Partial } \\
\eta^{2}\end{array}$ & $\begin{array}{l}\text { Observed } \\
\text { power }\end{array}$ \\
\hline \multirow[t]{2}{*}{ Time } & Pillai’s Trace & 0.015 & 53.967 & 1 & 3550 & 0.000 & 0.015 & 1.000 \\
\hline & Wilks' Lambda & 0.985 & 53.967 & 1 & 3550 & 0.000 & 0.015 & 1.000 \\
\hline \multirow[t]{2}{*}{ Time $\times$ Gender } & Pillai’s Trace & 0.009 & 30.781 & 1 & 3550 & 0.000 & 0.009 & 1.000 \\
\hline & Wilks' Lambda & 0.991 & 30.781 & 1 & 3550 & 0.000 & 0.009 & 1.000 \\
\hline \multirow[t]{2}{*}{ Time $\times$ Parental attitudes } & Pillai’s Trace & 0.016 & 18.716 & 3 & 3550 & 0.000 & 0.016 & 1.000 \\
\hline & Wilks' Lambda & 0.984 & 18.716 & 3 & 3550 & 0.000 & 0.016 & 1.000 \\
\hline \multirow[t]{2}{*}{ Time $\times$ Gender $\times$ Parental attitudes } & Pillai’s Trace & 0.012 & 13.99 & 3 & 3550 & 0.000 & 0.012 & 1.000 \\
\hline & Wilks' Lambda & 0.988 & 13.99 & 3 & 3550 & 0.000 & 0.012 & 1.000 \\
\hline
\end{tabular}

Table 3

ANOVA table for linear within-subjects contrasts in the adolescent alcohol consumption data

\begin{tabular}{lrlrrrrr}
\hline Source & $\begin{array}{l}\text { Type III } \\
\text { Sum of } \\
\text { Squares }\end{array}$ & df & $\begin{array}{l}\text { Mean } \\
\text { Square }\end{array}$ & $F$ & Sig. & $\begin{array}{l}\text { Partial } \\
\eta^{2}\end{array}$ & $\begin{array}{l}\text { Observed } \\
\text { power }\end{array}$ \\
\hline Time & 24.550 & 1 & 24.550 & 53.967 & 0.000 & 0.015 & 1.000 \\
Time $\times$ Gender & 14.003 & 1 & 14.003 & 30.781 & 0.000 & 0.009 & 1.000 \\
Time $\times$ Parental attitudes & 25.543 & 3 & 8.514 & 18.716 & 0.000 & 0.016 & 1.000 \\
Time $\times$ Gender $\times$ Parental attitudes & 19.092 & 3 & 6.364 & 13.990 & 0.000 & 0.012 & 1.000 \\
Error (Time) & 1614.944 & 3550 & 0.455 & & & & \\
\hline
\end{tabular}

Table 4

Tests of between-subjects effects in the adolescent alcohol consumption data

\begin{tabular}{|c|c|c|c|c|c|c|c|}
\hline Source & $\begin{array}{l}\text { Type III } \\
\text { Sum of } \\
\text { Squares }\end{array}$ & df & $\begin{array}{l}\text { Mean } \\
\text { Square }\end{array}$ & $F$ & Sig. & $\begin{array}{l}\text { Partial } \\
\eta^{2}\end{array}$ & $\begin{array}{l}\text { Observed } \\
\text { power }\end{array}$ \\
\hline Intercept & 6571.600 & 1 & 6571.600 & 7492.682 & 0.000 & 0.679 & 1.000 \\
\hline Gender & 27.146 & 1 & 27.146 & 30.951 & 0.000 & 0.009 & 1.000 \\
\hline Parental attitudes & 428.323 & 3 & 142.774 & 162.786 & 0.000 & 0.121 & 1.000 \\
\hline Gender $\times$ Parental attitudes & 22.369 & 3 & 7.456 & 8.502 & 0.000 & 0.007 & 0.994 \\
\hline Error & 3113.596 & 3550 & 0.877 & & & & \\
\hline
\end{tabular}

The results in Table 4 suggest that parental attitudes have an effect on the reported amount of alcohol consumption (see Figs. 1 and 2). More negative attitudes predict lower reported alcohol consumption. There is also a gender effect such that girls report, aggregated over both observation points, lower alcohol consumption than boys (see Figs. 1 and 2). In addition, there is 
an interaction between parental attitudes and gender (see again Figs. 1 and 2): boys respond more strongly to anticipated negative parental attitudes than do girls.

The observed power for these effects is 1 or close to 1 for all effects. However, as for the withinsubject effects, the portion of variance accounted for by the independent variables is very small. We next statistically illustrate some of the effects in this data set in more detail by discussing the parameters that can be estimated for the between-subjects effects. Table 5 displays these parameters by observation point. Redundant parameters are omitted.

The interpretation of these parameters rests on the comparison of the average of the dependent variable for the variable category that is indicated in the table, and the last category of that variable. For example, the parameter for Parental Attitudes (PA) $=1$ in the top panel of the table compares the cross-gender average level of self-reported alcohol consumption with that for category Parental Attitudes $(\mathrm{PA})=4$. The parameter is positive which suggests that adolescents report more drinking of alcoholic beverages when their parents express less negative attitudes. Table 5 suggests that, at Time 1, the first three categories of parental attitudes toward drinking result in higher reported amounts of drinking than the last category, that is, the one with the most negative parental attitudes.

The first parameter for the interaction of parental attitudes with gender $($ Gender $=1, \mathrm{PA}=1)$ suggests that this last statement is not gender specific. In contrast, the following two parameters are gender-specific. They suggest, as one can confirm by inspecting Figs. 1 and 2, that the parental attitude effects are, at Time 1, stronger in the male than in the female respondents. Note that this result applies regardless of total amount of reported alcohol consumption, which is higher in boys than in girls (see gender effect in Tables 4 and 5).

At Time 2, the effects are similar, but not exactly the same. We find largely the same parental attitude effects, but no more gender effect on the reported amount of alcohol consumption. This is an alternative way of expressing the Gender $\times$ Time interaction (see Table 3 ). In addition, the parameter for the gender-specificity of the $\mathrm{PA}=1$ versus $\mathrm{PA}=4$ contrast is now significant. Also in contrast to Time 1 , the parameter for the gender-specificity of the Gender $=1$ and $\mathrm{PA}=3$ contrast, which was significant at Time 1, fails to be significant at Time 2. This difference in the 2way interaction effects substantiates the three-way Time $\times$ Gender $\times$ Parental Attitude effect in Table 3.

To obtain further detail on the effect of parental attitudes, we compare the reported frequencies of alcohol consumption for scale-adjacent levels of the attitude scale. Results suggest that there is no difference in reported drinking between scale points 1 and 2 . These are the scale points that indicate that the parents would be not or only a little upset by their adolescent children's drinking of alcohol. All other comparisons of drinking for scale-adjacent levels of parental attitudes indicate significant differences.

We note again that none of the partial $\eta^{2}$ estimates suggests large effects. This applies both to the overall main effects and to the individual parameters. These analyses have not begun to exhaust the possible variable-oriented approaches to the data. There are additional and more detailed questions concerning mean differences that might be asked. For example, one can compare the means of the boys across the levels of the parental attitude scale aggregated over time, at a particular time point, or over two observation points. The same can be done for girls. These comparisons can be part of the Time $\times$ Attitude $\times$ Gender interaction, they can be part of an elaborate series of post hoc tests, or they can be modeled in the form of planned comparisons. 


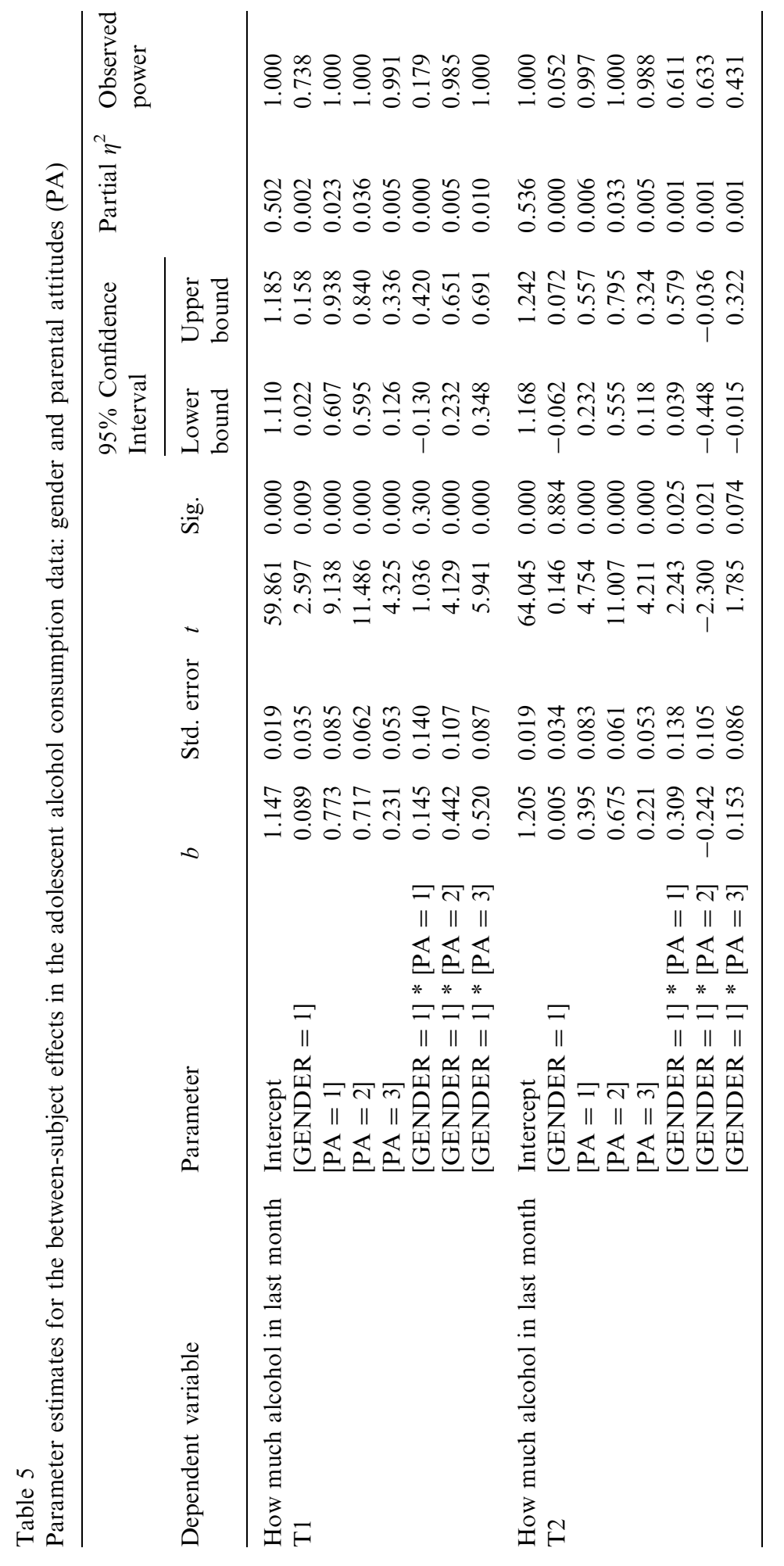


Person-oriented analysis: configural frequency analysis

In this section, we ask different questions. We noted above that the variable orientation to the data analysis resulted in small effect sizes for both between and within-group findings. Here we are not interested in relationships among variables for the group as a whole; rather, we ask whether specific subgroups within the sample can be identified that better explain the data. As the examples presented earlier in the article show, and as was apparent in the discussion of Molenaar's manifesto (von Eye, 2004; see also von Eye, Mun, \& Indurkhya, 2004), groups can be identified (1) using the means of statistics, for instance, cluster analysis, latent class analysis, or other methods of grouping of cases. These methods typically lead to a relatively small number of groups that show group-specific profiles in the variables on which the grouping was based, and that, given external validity, also differ in variables that were not used for the identification of the groups. In addition, these methods include the option of creating groups that differ in size, the most extreme case being that groups can be constituted by just one case. This flexibility is of importance from the perspective of person-oriented research.

A second method of creating groups involves crossing categorical variables. This method, commonly applied in the context of, for instance, log-linear modeling, correspondence analysis, latent class analysis, or CFA, exploits the fact that the probabilities of variable categories and thus patterns of variable categories, also called configurations, are not necessarily equal. Again, groups that differ in size can result.

Crossed categorical variables can be analysed with four aims in mind (Goodman, 1984; von Eye \& Gutiérrez-Peña, 2004): (1) analysing the joint distribution of the crossed variables; (2) analysing the association structure of the crossed variables; (3) analysing the dependency structure of the crossed variables; and (4) analysing local relationships in the space of the crossed variables. The first three aims can be pursued from both the variable- and the person-oriented perspectives. The fourth aim is typical of person-oriented research and is the approach that we take here.

Specifically, we examine whether particular patterns of the variables Gender, Parental Attitude, Alcohol Consumption at T1, and Alcohol Consumption at T2 occur more likely (or less likely) than chance. We exploit the fact that this design is non-orthogonal (cell frequencies are unequal). For the above ANOVA, we ignored this fact. The F- and the $t$-tests that were reported above, perform well. They are known to be robust. However, as can be seen in Table 1, the cell frequencies varied between 58 and 2664. This discrepancy sometimes causes problems, even for robust tests. The key issue is this: What may be a problem for the application of ANOVA is the basis of the analyses of the non-uniform frequency distribution of the cross-classification of the four variables under study.

We ask two kinds of questions in the following analyses using CFA. First, do particular configurations of the four crossed variables stand out such that they contain significantly more or fewer cases than expected based on some chance model? Second, are there differences between the females and the males in the present data? Both of these questions require specific, but different base models.

The first question is qualitatively different than the questions answered using ANOVAs. Using ANOVAs, we compare means of two or more cells, thereby disregarding possible differences in the numbers of cases in these cells. Here, we ask questions concerning the number of cases in individual cells, regardless of their means. 
If we ask questions concerning the frequencies in particular cells, we need to specify a base model. Base models create a reference to which the observed cell frequency is compared. This reference comes in the form of an estimated expected cell frequency. The base model that we use in the first-order CFA of the alcohol consumption data is that of variable independence. In other words, this base model accounts for all main effects of all variables; thus, types and antitypes only emerge if there are significant interactions. If a particular cell contains more cases than expected under this base model - this cell constitutes a type. In other words, the cell indicates a local variable relationship; that is, a relationship that exists only in this particular sector of the crossclassification. This relationship describes only the individuals in this cell. Accordingly, if a cell contains fewer cases than expected under the base model - this cell constitutes an antitype. It also indicates a local relationship. Cells that are not types or antitypes indicate those that have the number of cases one would expect.

\section{First-order configural frequency analysis}

In this section, we analyse the cross-classification of the variables Gender, Parental Attitudes, Alcohol Consumption at T1, and Alcohol Consumption at T2. Because of the large sample size, we are able to cross variables at the level of item responses or categories. Gender has two categories $(1=$ male; $2=$ female $)$, Parental Attitudes has 4 possible responses $(1=$ not upset at all; $2=$ a little upset $; 3=$ pretty upset ; and $4=$ very upset $)$, and Alcohol Consumption has 6 possible responses $(1=$ no drinks in last month; $2=1-2$ drinks; $3=3-5$ drinks; $4=6-9$ drinks; $5=10-19$ drinks; and $6=20-31$ drinks). Crossing these 12 responses/categories with each other results in 288 possible classifications (e.g., $1121=$ a male respondent who believes his parents are not upset at all about his drinking and who drank 1-2 days in the last month at T1 and no days in the last month at T2).

For the analysis, we employ a variant of standard CFA (Lienert \& Krauth, 1975; von Eye, 2002) with which we answer the question whether particular configurations, that is, patterns of these four variables, were observed more often (types), less often (antitypes), or about as often as expected. The expected frequencies are estimated under the assumption of variable independence. If this assumption is violated, variable associations must exist. However, instead of modeling these associations, we look for types and antitypes at the level of individual cells. These individual cell deviations from the assumption of variable independence carry the statement that variables are associated, at least locally. Table 6 displays the observed and the expected cell frequencies of the Gender $\times$ Parental Attitudes $\times$ Alcohol Consumption at T1 $\times$ Alcohol Consumption at T2 cross-classification of the adolescents' responses.

In the configural analysis, individual cells are examined, if the overall goodness-of-fit tests indicate that the model of variable independence is not tenable. The base model of independence for the present cross-classification is

$$
\log \hat{m}=\lambda+\lambda_{i}^{\text {Gender }}+\lambda_{j}^{\text {Parental attitudes }}+\lambda_{k}^{\text {Alcohol T1 }}+\lambda_{k}^{\text {Alcohol T2 }},
$$

where $\hat{m}$ is the array of expected frequencies, the $\lambda$ s are the estimated parameters, the subscripts index the parameters, and the superscripts index the variable for which a parameter is estimated.

The $\lambda \mathrm{s}$ in this equation have only one subscript. This indicates that the present model of CFA takes only main effects into account (model of variable independence). For the present data, 
Table 6

Observed and expected frequencies for $\mathrm{CFA}^{\mathrm{a}}$

\begin{tabular}{|c|c|c|c|c|c|c|c|}
\hline \multirow{2}{*}{$\begin{array}{l}\text { Parent } \\
\text { attitudes }\end{array}$} & \multirow{2}{*}{$\begin{array}{l}\text { T1 alcohol } \\
\text { consumption }\end{array}$} & \multicolumn{6}{|c|}{ T2 alcohol consumption } \\
\hline & & 1 & 2 & 3 & 4 & 5 & 6 \\
\hline \multicolumn{8}{|l|}{ Males } \\
\hline \multirow[t]{11}{*}{1} & 1 & $\begin{array}{c}21.000 \\
(34.418)\end{array}$ & $\begin{array}{c}2.000 \\
(4.258)\end{array}$ & $\begin{array}{c}1.000 \\
(1.537)\end{array}$ & $\begin{array}{c}1.000 \\
(0.762)\end{array}$ & $\begin{array}{c}0.000 \\
(0.364)\end{array}$ & $\begin{array}{c}1.000 \\
(0.399)\end{array}$ \\
\hline & 2 & 8.000 & 1.000 & 1.000 & 2.000 & 0.000 & 1.000 \\
\hline & & $(4.289)$ & $(0.531)$ & $(0.191)$ & $(0.095)$ & $(0.045)$ & $(0.050)$ \\
\hline & 3 & 4.000 & 3.000 & 2.000 & 1.000 & 0.000 & 1.000 \\
\hline & & $(1.548)$ & $(0.191)$ & $(0.069)$ & $(0.034)$ & $(0.016)$ & $(0.018)$ \\
\hline & 4 & 0.000 & 1.000 & 1.000 & 0.000 & 0.000 & 0.000 \\
\hline & & $(0.733)$ & $(0.091)$ & $(0.033)$ & $(0.016)$ & $(0.008)$ & $(0.008)$ \\
\hline & 5 & 2.000 & 0.000 & 1.000 & 0.000 & 0.000 & 1.000 \\
\hline & & $(0.614)$ & $(0.076)$ & $(0.027)$ & $(0.014)$ & $(0.006)$ & $(0.007)$ \\
\hline & 6 & 1.000 & 0.000 & 1.000 & 0.000 & 0.000 & 0.000 \\
\hline & & $(0.437)$ & $(0.054)$ & $(0.020)$ & $(0.010)$ & $(0.005)$ & $(0.005)$ \\
\hline \multirow[t]{12}{*}{2} & 1 & 35.000 & 7.000 & 1.000 & 0.000 & 0.000 & 1.000 \\
\hline & & $(3.825)$ & (7.897) & $(2.850)$ & (1.414) & $(0.674)$ & $(0.740)$ \\
\hline & 2 & 15.000 & 4.000 & 2.000 & 0.000 & 0.000 & 1.000 \\
\hline & & (7.954) & $(0.984)$ & $(0.355)$ & $(0.176)$ & $(0.084)$ & $(0.092)$ \\
\hline & 3 & 8.000 & 0.000 & 0.000 & 2.000 & 0.000 & 0.000 \\
\hline & & $(2.870)$ & $(0.355)$ & $(0.128)$ & $(0.064)$ & $(0.030)$ & $(0.033)$ \\
\hline & 4 & 3.000 & 2.000 & 1.000 & 1.000 & 2.000 & 0.000 \\
\hline & & (1.358) & $(0.168)$ & $(0.061)$ & $(0.030)$ & $(0.014)$ & $(0.016)$ \\
\hline & 5 & 5.000 & 0.000 & 0.000 & 3.000 & 0.000 & 0.000 \\
\hline & & (1.139) & $(0.141)$ & $(0.051)$ & $(0.025)$ & $(0.012)$ & $(0.013)$ \\
\hline & 6 & 5.000 & 1.000 & 0.000 & 1.000 & 1.000 & 0.000 \\
\hline & & $(0.811)$ & $(0.100)$ & $(0.036)$ & $(0.018)$ & $(0.009)$ & $(0.009)$ \\
\hline \multirow[t]{12}{*}{3} & 1 & 88.000 & 11.000 & 3.000 & 1.000 & 3.000 & 2.000 \\
\hline & & $(96.500)$ & (11.939) & (4.309) & $(2.138)$ & (1.020) & (1.118) \\
\hline & 2 & 10.000 & 6.000 & 0.000 & 1.000 & 0.000 & 1.000 \\
\hline & & $(12.025)$ & $(1.488)$ & $(0.537)$ & $(0.266)$ & $(0.127)$ & $(0.139)$ \\
\hline & 3 & 8.000 & 1.000 & 1.000 & 1.000 & 0.000 & 1.000 \\
\hline & & $(4.340)$ & $(0.537)$ & $(0.194)$ & $(0.096)$ & $(0.046)$ & $(0.050)$ \\
\hline & 4 & 9.000 & 0.000 & 3.000 & 0.000 & 1.000 & 0.000 \\
\hline & & $(2.054)$ & $(0.254)$ & $(0.092)$ & $(0.046)$ & $(0.022)$ & $(0.024)$ \\
\hline & 5 & 7.000 & 1.000 & 0.000 & 2.000 & 1.000 & 1.000 \\
\hline & & $(1.723)$ & $(0.213)$ & $(0.077)$ & $(0.038)$ & $(0.018)$ & $(0.020)$ \\
\hline & 6 & 4.000 & 3.000 & 0.000 & 0.000 & 1.000 & 0.000 \\
\hline & & $(1.226)$ & $(0.152)$ & $(0.055)$ & $(0.027)$ & $(0.013)$ & $(0.014)$ \\
\hline \multirow[t]{6}{*}{4} & 1 & 655.000 & 41.000 & 11.000 & 3.000 & 3.000 & 4.000 \\
\hline & & $(580.308)$ & (71.797) & $(25.910)$ & (12.856) & $(6.131)$ & $(6.725)$ \\
\hline & 2 & 37.000 & 12.000 & 2.000 & 1.000 & 0.000 & 0.000 \\
\hline & & $(72.314)$ & $(8.947)$ & $(3.229)$ & $(1.602)$ & $(0.764)$ & $(0.838)$ \\
\hline & 3 & 4.000 & 5.000 & 0.000 & 2.000 & 2.000 & 1.000 \\
\hline & & (26.097) & (3.229) & $(1.165)$ & $(0.578)$ & $(0.276)$ & $(0.302)$ \\
\hline
\end{tabular}


Table 6 (continued)

\begin{tabular}{|c|c|c|c|c|c|c|c|}
\hline \multirow{2}{*}{$\begin{array}{l}\text { Parent } \\
\text { attitudes }\end{array}$} & \multirow{2}{*}{$\begin{array}{l}\text { T1 alcohol } \\
\text { consumption }\end{array}$} & \multicolumn{6}{|c|}{ T2 alcohol consumption } \\
\hline & & 1 & 2 & 3 & 4 & 5 & 6 \\
\hline & 4 & 5.000 & 2.000 & 2.000 & 1.000 & 0.000 & 0.000 \\
\hline & & $(12.351)$ & $(1.528)$ & $(0.551)$ & $(0.274)$ & $(0.131)$ & $(0.143)$ \\
\hline & 5 & 7.000 & 0.000 & 1.000 & 2.000 & 0.000 & 1.000 \\
\hline & & $(10.359)$ & $(1.282)$ & $(0.463)$ & $(0.229)$ & $(0.109)$ & $(0.120)$ \\
\hline & 6 & 3.000 & 0.000 & 0.000 & 1.000 & 0.000 & 0.000 \\
\hline & & $(7.371)$ & $(0.912)$ & $(0.329)$ & $(0.163)$ & $(0.078)$ & $(0.085)$ \\
\hline \multicolumn{8}{|l|}{ Females } \\
\hline \multirow[t]{12}{*}{1} & 1 & 39.000 & 5.000 & 2.000 & 2.000 & 0.000 & 0.000 \\
\hline & & $(72.253)$ & $(8.939)$ & $(3.226)$ & $(1.601)$ & $(0.763)$ & $(0.837)$ \\
\hline & 2 & 18.000 & 8.000 & 2.000 & 0.000 & 0.000 & 1.000 \\
\hline & & $(9.004)$ & (1.114) & $(0.402)$ & (0.199) & $(0.095)$ & $(0.104)$ \\
\hline & 3 & 3.000 & 6.000 & 3.000 & 0.000 & 1.000 & 0.000 \\
\hline & & (3.249) & $(0.402)$ & $(0.145)$ & $(0.072)$ & $(0.034)$ & $(0.038)$ \\
\hline & 4 & 2.000 & 1.000 & 1.000 & 0.000 & 0.000 & 0.000 \\
\hline & & (1.538) & $(0.190)$ & $(0.069)$ & $(0.034)$ & $(0.016)$ & $(0.018)$ \\
\hline & 5 & 2.000 & 1.000 & 1.000 & 0.000 & 1.000 & 0.000 \\
\hline & & $(1.290)$ & $(0.160)$ & $(0.058)$ & $(0.029)$ & $(0.014)$ & $(0.015)$ \\
\hline & 6 & 0.000 & 0.000 & 1.000 & 0.000 & 0.000 & 0.000 \\
\hline & & $(0.918)$ & $(0.114)$ & $(0.041)$ & $(0.020)$ & $(0.010)$ & $(0.011)$ \\
\hline \multirow[t]{12}{*}{2} & 1 & 76.000 & 20.000 & 6.000 & 1.000 & 1.000 & 0.000 \\
\hline & & (133.988) & (16.577) & $(5.982)$ & (2.968) & (1.416) & (1.553) \\
\hline & 2 & 16.000 & 16.000 & 10.000 & 2.000 & 1.000 & 0.000 \\
\hline & & (16.697) & $(2.066)$ & $(0.745)$ & $(0.370)$ & $(0.176)$ & $(0.193)$ \\
\hline & 3 & 3.000 & 8.000 & 8.000 & 2.000 & 2.000 & 1.000 \\
\hline & & $(6.026)$ & $(0.745)$ & $(0.269)$ & $(0.133)$ & $(0.064)$ & $(0.070)$ \\
\hline & 4 & 0.000 & 3.000 & 3.000 & 1.000 & 1.000 & 1.000 \\
\hline & & $(2.852)$ & $(0.353)$ & $(0.127)$ & $(0.063)$ & $(0.030)$ & $(0.033)$ \\
\hline & 5 & 1.000 & 0.000 & 1.000 & 0.000 & 0.000 & 2.000 \\
\hline & & $(2.392)$ & $(0.296)$ & $(0.107)$ & $(0.053)$ & $(0.025)$ & $(0.028)$ \\
\hline & 6 & 3.000 & 1.000 & 1.000 & 0.000 & 0.000 & 1.000 \\
\hline & & $(1.702)$ & $(0.211)$ & $(0.076)$ & $(0.038)$ & $(0.018)$ & $(0.020)$ \\
\hline \multirow[t]{12}{*}{3} & 1 & 172.000 & 20.000 & 6.000 & 2.000 & 1.000 & 0.000 \\
\hline & & (202.583) & $(25.064)$ & $(9.045)$ & $(4.488)$ & $(2.140)$ & $(2.348)$ \\
\hline & 2 & 24.000 & 19.000 & 2.000 & 2.000 & 1.000 & 1.000 \\
\hline & & $(25.245)$ & $(3.123)$ & (1.127) & $(0.559)$ & $(0.267)$ & $(0.293)$ \\
\hline & 3 & 4.000 & 3.000 & 3.000 & 4.000 & 1.000 & 0.000 \\
\hline & & $(9.110)$ & (1.127) & $(0.407)$ & $(0.202)$ & $(0.096)$ & $(0.106)$ \\
\hline & 4 & 2.000 & 0.000 & 2.000 & 0.000 & 0.000 & 0.000 \\
\hline & & $(4.312)$ & $(0.533)$ & $(0.193)$ & $(0.096)$ & $(0.046)$ & $(0.050)$ \\
\hline & 5 & 1.000 & 0.000 & 0.000 & 1.000 & 1.000 & 0.000 \\
\hline & & (3.616) & $(0.447)$ & $(0.161)$ & $(0.080)$ & $(0.038)$ & $(0.042)$ \\
\hline & 6 & 172.000 & 20.000 & 6.000 & 2.000 & 0.000 & 0.000 \\
\hline & & (2.573) & $(0.318)$ & $(0.115)$ & $(0.057)$ & $(0.027)$ & $(0.030)$ \\
\hline
\end{tabular}


Table 6 (continued)

\begin{tabular}{|c|c|c|c|c|c|c|c|}
\hline \multirow{2}{*}{$\begin{array}{l}\text { Parent } \\
\text { attitudes }\end{array}$} & \multirow{2}{*}{$\begin{array}{l}\text { T1 alcohol } \\
\text { consumption }\end{array}$} & \multicolumn{6}{|c|}{ T2 alcohol consumption } \\
\hline & & 1 & 2 & 3 & 4 & 5 & 6 \\
\hline \multirow[t]{6}{*}{4} & 1 & $\begin{array}{c}1529.000 \\
(1218.243)\end{array}$ & $\begin{array}{c}92.000 \\
(150.723)\end{array}$ & $\begin{array}{c}23.000 \\
(54.393)\end{array}$ & $\begin{array}{c}12.000 \\
(26.989)\end{array}$ & $\begin{array}{c}4.000 \\
(12.872)\end{array}$ & $\begin{array}{c}5.000 \\
(14.117)\end{array}$ \\
\hline & 2 & $\begin{array}{c}68.000 \\
(151.810)\end{array}$ & $\begin{array}{c}43.000 \\
(18.782)\end{array}$ & $\begin{array}{l}13.000 \\
(6.778)\end{array}$ & $\begin{array}{c}7.000 \\
(3.363)\end{array}$ & $\begin{array}{c}1.000 \\
(1.604)\end{array}$ & $\begin{array}{c}3.000 \\
(1.759)\end{array}$ \\
\hline & 3 & $\begin{array}{c}10.000 \\
(54.785)\end{array}$ & $\begin{array}{c}6.000 \\
(6.778)\end{array}$ & $\begin{array}{l}3.000 \\
(2.446)\end{array}$ & $\begin{array}{l}2.000 \\
(1.214)\end{array}$ & $\begin{array}{l}1.000 \\
(0.579)\end{array}$ & $\begin{array}{c}0.000 \\
(0.635)\end{array}$ \\
\hline & 4 & $\begin{array}{c}2.000 \\
(25.929)\end{array}$ & $\begin{array}{c}3.000 \\
(3.208)\end{array}$ & $\begin{array}{c}4.000 \\
(1.158)\end{array}$ & $\begin{array}{l}1.000 \\
(0.574)\end{array}$ & $\begin{array}{c}0.000 \\
(0.274)\end{array}$ & $\begin{array}{l}1.000 \\
(0.300)\end{array}$ \\
\hline & 5 & $\begin{array}{c}2.000 \\
(21.747)\end{array}$ & $\begin{array}{l}1.000 \\
(2.691)\end{array}$ & $\begin{array}{l}1.000 \\
(0.971)\end{array}$ & $\begin{array}{c}0.000 \\
(0.482)\end{array}$ & $\begin{array}{c}0.000 \\
(0.230)\end{array}$ & $\begin{array}{l}1.000 \\
(0.252)\end{array}$ \\
\hline & 6 & $\begin{array}{c}3.000 \\
(15.474)\end{array}$ & $\begin{array}{c}4.000 \\
(1.914)\end{array}$ & $\begin{array}{c}1.000 \\
(0.691)\end{array}$ & $\begin{array}{c}0.000 \\
(0.343)\end{array}$ & $\begin{array}{c}0.000 \\
(0.163)\end{array}$ & $\begin{array}{c}0.000 \\
(0.179)\end{array}$ \\
\hline
\end{tabular}

${ }^{\mathrm{a}}$ Expected frequencies in parentheses.

we find that the base model of independence is rejected $\left(\mathrm{LR} \chi^{2}=1374.95 ; \mathrm{df}=273 ; p<0.01\right)$. We thus proceed and examine the individual cells.

In the present case, and, in general, in most CFA applications, the individual cell tests are, to a certain degree, dependent (Krauth, 2003; von Weber, Lautsch, \& von Eye, 2003), and the application of a large number of significance tests to the same data involves a high risk of capitalizing on chance. Therefore, CFA applications always come with procedures to protect the significance threshold $\alpha$. The most popular, yet conservative, procedure is Bonferroni's method, which yields the adjusted $\alpha^{*}=\alpha / t$, where the adjustment takes the number of cells in a crossclassification, $t$, into account. For Table 6, we obtain an adjusted threshold of $\alpha^{*}=0.05 /$ $(2 \times 4 \times 6 \times 6)=0.0001736$. The $\chi^{2}$ for this extreme alpha for $1 \mathrm{df}$ is 12.7969 . The $\chi^{2}$ values can be calculated from the observed and expected frequencies in Table $6 \cdot \chi^{2}=(\text { observed-expected })^{2} /$ expected. Based on a threshold this extreme, only substantial differences between observed and expected cell frequencies will emerge as types and antitypes.

A complication that is specific to the present data set is that a large number of expected cell frequencies are small, where "small," for the present purposes, means that the approximation characteristics of $\chi^{2}$ may not be satisfactory any more. Therefore, we apply a modified CFA routine. Instead of examining each individual cell, we just examine those cells that have expected cell frequencies greater than $\hat{m}_{i j k l}=0.5$. Under this a priori condition, some of the asymptotic tests still have defensible approximation characteristics.

The procedure that used the above-specified $\alpha^{*}$ and this a priori selection criterion led to the detection of 9 antitypes and 10 types.

Antitypes. The 9 antitypes are described below.

1421: $\quad 37$ boys had this pattern, but more than 72 had been expected. It is less likely than chance that male respondents whose parents would be very upset about their 
drinking drank on 1-2 days in the month before $\mathrm{T} 1$ and not at all in the month before $\mathrm{T} 2$.

2111: 39 girls showed this pattern, but over 72 had been expected. It is very unlikely to find girls who think their parents would not be upset at all at their drinking and do not drink at $\mathrm{T} 1$ and at $\mathrm{T} 2$.

2211: $\quad 76$ girls exhibited this pattern, but almost 134 had been expected. It is very unlikely to find girls who think their parents would be a little upset at all at their drinking and do not drink at T1 and T2.

2421: 68 girls showed this pattern, but almost 152 had been expected. It thus is very unlikely to find girls who perceive their parents as very upset at their drinking and drink at a rate of 1-2 days per month at $\mathrm{T} 1$ and not at all at $\mathrm{T} 2$.

2431-2451: the same is found for girls who drink between 3-5 days and 10-19 days per month at $\mathrm{T} 1$ and nothing at $\mathrm{T} 2$.

2412: $\quad 92$ girls showed this pattern, but over 150 had been expected. It is thus very unlikely to find girls who perceive their parents as very upset at their drinking and do not drink at $\mathrm{T} 1$ and at a rate of 1-2 days per month at $\mathrm{T} 2$.

2413: 23 girls showed this pattern but over 53 had been expected. It is thus very unlikely to find girls who perceive their parents as very upset at their drinking and do not drink at $\mathrm{T} 1$ and at a rate of $3-5$ days per month at $\mathrm{T} 2$.

These 9 antitypes show a very interesting pattern. First, with only one exception (antitype 1421), the antitypes describe only girls. The only boy antitype complements a girl antitype with the exact same response pattern. Second, with only 2 exceptions, each antitype ends with drinking pattern 1. These are respondents who indicate that they did not drink alcohol at all in the month before the second survey. Third, half of the antitypes suggest that the respondents drank at T1 but did not drink at T2. It is thus extremely unlikely that these adolescents had started drinking alcohol before $\mathrm{T} 1$ and then refrained from it, even in the face of parents who are perceived as very upset at the adolescents' drinking. Fourth, with only two exceptions (2111 and 2211), each of the antitypes was observed for adolescents who reported that their parents would be very upset at the adolescents' drinking. It thus seems that some of the parents who are perceived as very upset at their adolescents' drinking can expect their children not to refrain once they have started drinking at T1.

All these patterns are less likely than chance. In different words, it is unlikely to find girls and boys who reduce their drinking from above zero at $\mathrm{T} 1$ to zero at $\mathrm{T} 2$ and who have parents whom the adolescents anticipate to respond aversely to their drinking.

Types. Ten types were found in the first-order CFA; that is, it is more likely than chance to find adolescents with these profiles. These are described below.

1322: 6 boys showed this pattern, but only about 1 had been expected. These boys see their parents as pretty upset at their drinking, and keep their drinking rates at 1-2 days in both months before $\mathrm{T} 1$ and $\mathrm{T} 2$.

1341: 9 boys found, only 2 expected. These boys see their parents as pretty upset at their drinking, and reduce their drinking rates from 6-9 days in the month before T1 to none in the month before $\mathrm{T} 2$. 
1351: 7 boys found, fewer than 2 expected. These boys see their parents as pretty upset at their drinking, and reduce their drinking rates from 10-19 days in the month before T1 to none in the month before $\mathrm{T} 2$.

2122: 8 girls found, only about 1 expected. These girls see their parents as not upset at all at their drinking, and keep their drinking rates at 1-2 days in both months before T1 and $\mathrm{T} 2$.

2222: 16 girls found, about 2 expected. It is more likely than chance to find girls who indicate that their parents would be a little upset about their drinking and who drank on 1-2 days in the month before $\mathrm{T} 1$ as well as in the month before $\mathrm{T} 2$.

2223: 10 girls found, about 1 expected. It is more likely than chance to find girls who say that their parents would be a little upset about their drinking and who drank on 1-2 days in the month before T1, and increased their drinking to 3-5 days in the month before T2.

2232: 8 girls found, about 1 expected. It is more likely than chance to find girls who say that their parents would be a little upset about their drinking, who drank on 3-5 days in the month before T1, and reduced their drinking to 1-2 days in the month before T2.

2322: 19 girls found, about 3 expected. It is more likely than chance to find girls who indicate that their parents would be pretty upset about their drinking and who drank on 1-2 days in the months before both surveys.

2411: 1529 girls found, about 1218 expected. This is the largest group of girls. These girls expect their parents to be very upset at their drinking, and report not drinking at all on both occasions.

2422: 43 girls found, fewer than 19 expected. These girls expect their parents to be very upset at their drinking, and report drinking at a rate of 1-2 days per month at both occasions.

Overall, seven of the 10 types describe girls. For all seven of these types and one of the types that describe boys (1322), it is far more likely than expected based on chance to find adolescents who drink nothing or moderate amounts, and who change their drinking habits either not at all or only slightly in the time period between the two surveys.

Discussion of CFA results. The CFA results presented in the last paragraphs can be used to highlight three characteristics of CFA results that are most likely to occur (von Eye \& GutiérrezPeña, 2004). First, in practically all cases, only a selection of configurations constitutes types and antitypes. In different words, in some cells of the cross-classification, the base model prevails, whereas in other cells, there are significant deviations. It is possible, in some analyses, that all or none of the configurations will constitute types or antitypes. The present pattern of results, however, is most typical for empirical data.

Second, not necessarily the largest frequencies result in types or the smallest frequencies result in antitypes. In the present example, the latter is the case. The largest frequency, 1529, observed for configuration 2411 is significantly larger than expected. The same does not apply to the second largest frequency of 655, observed for configuration 1411. For this configuration, we also find more cases than expected, but this difference is not significant. These are girls and boys who expect their parents to respond very aversely to their drinking, and do not drink at all in the months before the surveys. At the low-frequency end, none of the cells with zero frequencies 
constituted an antitype. As soon as a base model takes at least main effects into account, types and antitypes are no longer confounded with the size of the cell. There is only one CFA base model in which the largest cells constitute types and the smallest cells constitute antitypes. This is the model of zero order CFA, which is a null model.

Third, after having identified types and antitypes, researchers do not attempt to specify a better fitting model. Instead, they describe and interpret the patterns of the types and antitypes, and they often ask whether there is external validity such that the types and antitypes differ from the less suspect cases in the space of other variables too. For example, Bogat and von Eye (2005) used CFA to create a typology of mother/child dyads based on whether, over time, the mother had experienced intimate partner violence (yes/no), and, if she had, whether her child had witnessed it (yes/no). In a step after the CFA application, they asked whether the cases found in the types differed from each other on maternal depression and child internalizing and externalizing behaviour. Thus, CFA is a typological approach to the analysis of cross-classifications, not a model fitting approach. (Because the purpose of this article is methodological, a test of the external validity of the type and antitype clusters is not undertaken here.)

\section{A gender comparison using 2-sample CFA}

The configural analyses above suggested that, in large parts of the Gender $\times$ Parental Attitudes $(\mathrm{PA}) \times$ Alcohol Consumption at T1 (AT1) $\times$ Alcohol Consumption at T2 (AT2) crossclassification, the boys and girls do not show comparable response patterns. Only one of the antitypes and one of the types was found both in the girls' and in the boys' samples. Gender differences may thus exist. Therefore, we examine this cross-classification under a base model that is suitable for the analysis of the differences between two groups of responses, 2-sample CFA. This base model is saturated in the variables used to discriminate between two groups of respondents. That is, all possible variable relationships among those variables are part of the base model. In addition, this model proposes that the variable that indicates the groups is independent of all other variables. Thus, types can occur only if the two groups differ in particular patterns of the variables used for discrimination. The log-linear base model for the present crossclassification is

$$
\begin{aligned}
\log \hat{m}= & \lambda+\lambda_{i}^{\text {Gender }}+\lambda_{j}^{\mathrm{PA}}+\lambda_{k}^{\mathrm{AT} 1}+\lambda_{l}^{\mathrm{AT} 2} \\
& +\lambda_{j k}^{\mathrm{PA} \times \mathrm{AT} 1}+\lambda_{j l}^{\mathrm{PA} \times \mathrm{AT} 2}+\lambda_{k l}^{\mathrm{AT} 1 \times \mathrm{AT} 2}+\lambda_{j k l}^{\mathrm{PA} \times \mathrm{AT} 1 \times \mathrm{AT} 2},
\end{aligned}
$$

where the doubly subscripted and doubly superscripted terms indicate first-order interaction terms, and the term with triple subscripts and triple superscripts indicates the three-way interaction among the variables used to discriminate between the girls and the boys.

Obviously, this model is more complex than the one used for first-order CFA, thus it may be harder to detect gender differences. In other words, because more effects are taken into account, fewer possibilities exist to contradict the model. Indeed, 2-sample CFA did not indicate a single response pattern in which girls and boys differ significantly.

This result may be surprising because the type and antitype analysis showed only one antitype and one type that appeared in both gender groups. All other types and antitypes were genderspecific. However, gender-specific types and antitypes will not necessarily lead to the detection of gender differences. 
To explain, consider the type 2411 that was found in the girl sample. The corresponding configuration in the boy sample, 1411, did not constitute a type. However, in the boy sample, 655 respondents showed this pattern, whereas only about 580 had been expected. The Pearson $\chi^{2}$ for this discrepancy is 9.61 (in the girl sample, it was $\chi^{2}=79.27$ ), with $\mathrm{df}=1$ and $p=0.002$. Without $\alpha$-protection, this discrepancy would be significant. However, in CFA applications, $\alpha$ is routinely protected and, thus, this pattern does not constitute a type because $0.002>0.00017$. Now, as is obvious, the sign of the discrepancy is the same for girls and boys. In both samples, more respondents were found with this pattern than expected. This discrepancy was significant only for girls. However, because the orientation of the discrepancy was the same in the gender groups, the difference between the gender groups remained non-significant.

\section{Discussion}

The purpose of this paper was to exemplify person- and variable-oriented approaches to data analysis. As an example, we used data on adolescent drinking and parental attitudes about that drinking. For the variable-oriented approach, we chose to analyse the data using repeated measures ANOVA. The findings can be summarized as follows: Main effects - (1) boys drink more than girls, (2) the frequency of alcohol use decreases from T1 to T2, and (3) more negative parental attitudes are predictive of less drinking. First-order interactions- (1) for boys as compared to girls, a decrease in alcohol consumption is more pronounced and parental attitude effects on drinking are stronger, and (2) parental attitude effects are stronger at T1 than at T2. Second-order interactions - (1) parental attitude effects are weaker at T2 than at T1, in particular for boys.

A summary of the CFA results is different. The first-order CFA yielded 9 antitypes and 10 types. The following pattern of behaviours is particularly unlikely: parents very upset, the adolescent drinks at $\mathrm{T} 1$, the adolescent stops drinking at $\mathrm{T} 2$, and there are no gender-specific antitypes. The following pattern of behaviours occurs more likely than expected by chance: there is little change in the adolescent's drinking, the parents are less upset at adolescents drinking than in antitypes, and there are no gender-parallel behaviours. The 2-sample CFA indicated no significant gender differences.

Although quite different, the findings from the approaches can be seen as complementing each other. To demonstrate, we select one particular ANOVA result and present qualifications using selected CFA results. Our ANOVA indicated that, across both gender groups, alcohol consumption decreases from $\mathrm{T} 1$ to $\mathrm{T} 2$. There is a significant first-order interaction with gender such that this decrease is stronger in boys. Looking at this first-order interaction, we see that the decrease in alcohol consumption frequency is more pronounced in boys than in girls. Girls, overall, actually increased their drinking. However, the interaction comes with the rather small partial $\eta^{2}$ of 0.009 (see Table 2). Because of the colossal power that the large sample causes, this effect is significant yet explains little of the overall variation. We thus assume that either the statement that boys consume less alcohol at T2 or the statement that the girls increased their drinking (or both statements) may need to be qualified. Indeed, we find that CFA suggests that there exist behaviour patterns such that a small number of girls with little upset parents increase drinking more often (Pattern 2223) than expected by chance. And girls with very upset parents 
increase their drinking less often than expected by chance (Patterns 2412 and 2413). But there are also boys who increase their drinking as well. Thus, the CFA identifies gender-specific types, but there exists similar, yet non-significant, discrepancies from expectancy in the boy sample. We thus find a group of respondents who behave counter to the general trend that is indicated by the ANOVA results. This applies both to the overall trend and to the gender-specific trends found in the ANOVA.

Even stronger, the by far largest group of girls indicates, more often than expected by chance, in the presence of very upset parents, that they do not drink at all, at both occasions (Pattern 2411). Again, boys show the same, but non-significant tendency. The ANOVA results would lead one to conclude that, in general, girls and boys reduce their drinking. Looking at the gender-specific trends, one would conclude that boys reduce their drinking and girls slightly increase their drinking. Based on CFA, we conclude that most girls do not drink, so a reduction in drinking rate is, for these respondents, impossible by definition. This applies accordingly to the majority of boys.

Still, it should be noted that the CFA results do not invalidate the ANOVA results. The latter indicate general trends. However, based on the small effect sizes, we assumed that there may exist groups of respondents who behave differently. CFA was able to identify these respondents.

Substantively, two of the main effects from the ANOVA support the current literature: boys drink more than girls (e.g., Johnston et al., 2003; Robins \& Martin, 1993; Thomas, 1996) and more negative parental attitudes toward drinking are associated with less drinking (e.g., Ary et al., 1993; Bogenschneider et al., 1998; Halebsky, 1987; Yu, 1998, 2003). This latter finding substantiates findings indicating that competent behaviour regarding alcohol consumption is associated with parenting (Jackson et al., 1997). The result that drinking decreases from T1 to T2 is surprising given that research indicates that drinking generally increases over time (e.g., Duncan, Duncan, \& Hops, 1994) until early adulthood when it gradually decreases (e.g., Johnston, O’Malley, \& Bachman, 1996).

The CFA identifies groups of girls and boys who seem to be resilient to the enticements of drinking. For example, it is unlikely to find girls whose parents are not upset at all or a little upset by their drinking who do not drink at either time point. Alternatively, it is very likely to find girls whose parents are very upset by their drinking who do not drink at either time point. Thus, strong parental feelings about their drinking seem to be an effective way to enhance adolescence resilience to consuming alcohol.

There are some limitations to the findings reported here. First, for the purposes of the data analysis comparison, we did not take into account the age of the participants. The 4-way interaction that might have resulted would have been difficult or impossible to interpret. However, there may be, within this sample, age-related groups of individuals with different mean responses and different response patterns. For example, Li, Duncan, and Hops (2001) showed two distinct latent developmental trajectory classes resulting from either high or low alcohol use at Grade 6. The finding that drinking decreased from T1 to T2 may be an artifact of combining these distinct age-related groups. Second, adolescent perceptions of parent attitudes may or may not correspond to parent-expressed attitudes. Studies that query both parents and their children regarding alcohol-related matters often find differences between the two respondents (Smith, Miller, Kroll, Simmons, \& Gallen, 1999). Thus, the results of this study may not be replicated with parent report. Third, we did not examine amount of alcohol consumption. The days per month of 
drinking variable may have had an in-built ceiling effect. Young people may have difficulty increasing their days of drinking per month over time because of school obligations and parental supervision. Fourth, in addition, the relatively short period of time between the two assessments may have not allowed enough time for significant changes in alcohol consumption to occur. Fifth, most of the participants did not drink at all. And, sixth, there are many factors, in addition to gender and parent attitudes, that relate to adolescent's competent behaviour regarding alcohol. What are the implications of these results? First, neither the variable-oriented nor the personoriented approach produces results that render the respective other meaningless. Instead, each of the two approaches has the potential of enriching the respective other. Specifically, general trends may be important for researchers interested in testing hypotheses concerning the effects of variables or treatments in general, in well-specified populations. In contrast, the person-oriented approach identifies those individuals or groups of individuals who display their own behaviour patterns, that is, patterns that are unique and not found in the general population, or not represented by the aggregate-level average. Thus, general trends may exist, while individuals and groups of individuals may also exist that behave differently (without being outliers or exhibiting nothing but measurement error).

With regard to the methods employed here (ANOVA and CFA), the comparison of the personoriented and the variable-oriented approaches highlights another important implication. In ANOVA, cases that buck the trend are considered outliers, and reduce the strength of effects. Occasionally, researchers even discuss the elimination of outliers from analysis. In contrast, in person-oriented research, cases that show their unique behaviour patterns are deemed worthy of study, and, may be those who are most interesting. Methods such as CFA allow one to identify those cases, in addition to identifying general trends.

A third implication is that results from person- and variable-oriented research are stated in different terms. The latter expresses results in terms of variable effects or relationships. This applies also when structural models or other methods of analysis are used. The former expresses results by describing behaviour patterns, thus meeting Molenaar's (2004) desiderate of bringing the individual back into research in the social and behavioural sciences.

\section{References}

Andrews, J. A., Hops, H., Ary, D., Tildesey, E., \& Harris, J. (1993). Parental influences on early adolescent substance use: Specific and nonspecific effects. Journal of Early Adolescence, 13, 285-310.

Ary, D. V., Tildesley, E., Hops, H., \& Andrews, J. (1993). The influence of parent, sibling, and peer modeling and attitudes on adolescent use of alcohol. International Journal of Addictions, 28, 853-888.

Bergman, L. R., \& Magnusson, D. (1997). A person-oriented approach in research on developmental psychopathology. Development and Psychopathology, 9, 291-319.

Bogat, G. A., \& von Eye, A. (2005, August). Stability of domestic violence experiences among mother/child dyads. Paper presented as part of the Invited Symposium, Maltreatment and resilience, Paola Di Blasio \& María José Rodrigo (Conveners), XIIth European Conference on Developmental Psychology, Tenerife, Spain.

Bogenschneider, K., Wu, M., Raffaelli, M., \& Tsay, J. C. (1998). Parent influences on adolescent peer orientation and substance use: The interface of parenting practices and values. Child Development, 69, 1672-1688.

Duncan, T. E., Duncan, S. C., \& Hops, H. (1994). The effects of family cohesiveness and peer encouragement on the development of adolescent alcohol use: A cohort-sequential approach to the analysis of longitudinal data. Journal of Studies in Alcohol, 55, 588-599. 
Finkelstein, J. W., von Eye, A., \& Preece, M. A. (1994). The relationship between aggressive behaviour and puberty in normal adolescents: A longitudinal study. Journal of Adolescent Health, 15, 319-326.

Fitzgerald, J. L., \& Arndt, S. (2003). Reference group influence on adolescent alcohol use. Journal of Alcohol \& Drug Education, 47, 42-57.

Goodman, L. A. (1984). The analysis of cross-classified data having ordered categories. Cambridge, MA: Harvard University Press.

Griffin, K. W., Epstein, J. A., Botvin, G. J., \& Spoth, R. L. (2001). Social competence and substance use among rural youth: Mediating role of social benefit expectancies of use. Journal of Youth and Adolescence, 30, 485-498.

Halebsky, M. A. (1987). Adolescent alcohol and substance abuse: Parent and peer effects. Adolescence, 22, 961-967.

Jackson, C., Henriksen, L., Dickinson, D., \& Levine, D. (1997). The early use of alcohol and tobacco: Its relation to children's competence and parents' behaviour. American Journal of Public Health, 87, 359-364.

Johnston, L. D., O’Malley, P. M., \& Bachman, J. G. (1996). National survey results on drug use from The Monitoring the Future Study, 1975-1995, Vol. 1. NIH Publication No. 96-4139, Washington, DC: US Government Printing Office.

Johnston, L. D., O’Malley, P. M., \& Bachman, J. G. (2003). The monitoring the future national survey results on adolescent drug use: Overview of key findings. 2002. (NIH Publication No. 00-4690). Rockville, MD: National Institute on Drug Abuse, c 56pp.

Krauth, J. (2003). Type structures in CFA. Psychology Science, 45, 330-338.

Lerner, R. M., Lerner, J. V., Almerigi, J., Theokas, C., Naudeau, S., Gestsdottir, S., et al. (2005). Positive youth development; Participation in community youth development programs; And community contributions of fifth grade adolescents: Findings from the first wave of the 4-h study of positive youth development. Journal of Early Adolescence, 25, 17-71.

Li, F., Duncan, T. E., \& Hops, H. (2001). Examining developmental trajectories in adolescent alcohol use using piecewise growth mixture modeling analysis. Journal of Studies on Alcohol, 62, 199-210.

Lienert, G. A., \& Krauth, J. (1975). Configural frequency analysis as a statistical tool for defining tpyes. Educational and Psychological Measurement, 35, 231-238.

Molenaar, P. C. M. (2004). A manifesto on Psychology as idiographic science: Bringing the person back into scientific psychology_-This time forever. Measurement: Interdisciplinary Research and Perspectives, 2, 201-218.

O’Malley, P. M., Johnston, L. D., \& Bachman, J. G. (1998). Alcohol use among adolescents. Alcohol Health \& Research World, 22, 85-93.

Petraitis, J., Flay, B. R., \& Miller, T. Q. (1995). Reviewing theories of adolescent substance use: Organizing pieces in the puzzle. Psychological Bulletin, 117, 67-86.

Robins, C. A., \& Martin, S. S. (1993). Gender styles of deviance and drinking problems. Journal of Health and Social Behaviour, 34, 302-321.

Scheier, L. M., Botvin, G. J., Diaz, T., \& Griffin, K. W. (1999). Social skills, competence, and drug refusal efficacy as predictors of adolescent alcohol use. Journal of Drug Education, 29, 251-278.

Smith, G. T., Miller, T. L., Kroll, L., Simmons, J. R., \& Gallen, R. (1999). Children's perceptions of parental drinking: the eye of the beholder. Journal of Studies on Alcohol, 60, 817-824.

Springer, JF., Sale, E., Nistler, M., Kasim, R., \& Pan, W. (2000). The National Cross-Site Evaluation of High-Risk Youth Programs: Final technical report. Rockville, MD: Report to the US Department of Health and Human Services, Center for Substance Abuse Prevention.

Theokas, C., Almerigi, J., Lerner, R. M., Dowling, E. M., Benson, P., Scales, P., et al. (2005). Conceptualizing and modeling individual and ecological asset components of thriving in early adolescence. Journal of Early Adolescence, 25, 113-143.

Thomas, A., \& Chess, S. (1986). The New York Longitudinal Study: From infancy to early adult life. In R. Plomin, \& J. Dunn (Eds.), The study of temperament: Changes, continuities, and challenges (pp. 39-52). Hillsdale, NJ: Lawrence Erlbaum.

Thomas, B. S. (1996). A path analysis of gender differences in adolescent onset of alcohol, tobacco and other drug use (ATOD), reported ATOD use and adverse consequences of ATOD use. Journal of Addictive Disease, 15, 33-52.

Tubman, J. T., Lerner, R. M., Lerner, J. V., \& von Eye, A. (1992). Temperament and adjustment in young adulthood: A fifteen-year longitudinal analysis. American Journal of Orthopsychiatry, 62, 564-574. 
Tubman, J. T., Vicary, J. R., von Eye, A., \& Lerner, J. V. (1990). Longitudinal substance use and adult adjustment. Journal of Substance Abuse, 2, 317-334.

Tubman, J. G., Vicary, J. R., von Eye, A., \& Lerner, J. V. (1991). Qualitative changes in substance use-adjustment relations in adolescence. Journal of Substance Abuse, 3, 405-414.

Tubman, J. G., Wagner, E. F., \& Langer, L. M. (2003). Patterns of depressive symptoms, drinking motives, and sexual behaviour among substance abusing adolescents: Implications for health risk. Journal for Child \& Adolescent Substance Abuse, 13, 37-57.

von Eye, A. (2002). Configural Frequency Analysis-Methods, models, and applications. Mahwah, NJ: Lawrence Erlbaum.

von Eye, A. (2004). The treasures of Pandora's box. Measurement: Interdisciplinary Research and Perspectives, 2, 244-247.

von Eye, A., \& Bergman, L. R. (2003). Research strategies in developmental psychopathology: Dimensional identity and the person-oriented approach. Development and Psychopathology, 15, 553-580.

von Eye, A., \& Bogat, G. A. (2005). Methods of data analysis in person-oriented research. The sample case of ANOVA. Unpublished manuscript.

von Eye, A., \& Gutiérrez-Peña, E. (2004). Configural Frequency Analysis-The search for extreme cells. Journal of Applied Statistics, 31, 981-997.

von Eye, A., Mun, E. Y., \& Indurkhya, A. (2004). Classifying developmental trajectories-A decision making perspective. Psychology Science, 46, 65-98.

von Weber, S., Lautsch, E., \& von Eye, A. (2003). On the limits of Configural Frequency Analysis: Analyzing small tables. Psychology Science, 45, 339-354.

Webb, J. A., Bray, J. H., Getz, J. G., \& Adams, G. (2002). Gender, perceived parental monitoring, and behavioural adjustment: Influences on adolescent alcohol use. American Journal of Orthopsychiatry, 72, 392-400.

Yu, J. (1998). Perceived parental/peer attitudes and alcohol-related behaviors: An analysis of the impact of the drinking age law. Substance Use and Misuse, 33, 2687-2702.

Yu, J. (2003). The association between parental alcohol-related behaviors and children's drinking. Drug and Alcohol Dependence, 69, 253-262.

Yu, J., \& Perrine, M. W. (1997). The transmission of parent/adult-child drinking patterns: Testing a gender-specific structural model. American Journal of Drug and Alcohol Abuse, 23, 143-165. 